\title{
A ÁREA CTS NO BRASIL VISTA COMO REDE SOCIAL: ONDE APRENDEMOS?
}

\section{Brazilian STS viewed as social network: where shall we learn?}

\author{
Alvaro Chrispino ${ }^{1}$. Leonardo Silva de Lima² . Márcia Bengio de \\ Albuquerque $^{3}$. Ana Claudia Carvalho de Freitas ${ }^{4}$. Marco Aurélio
}

Ferreira Brasil da Silva ${ }^{5}$

\begin{abstract}
Resumo: O presente trabalho apresenta o resultado de levantamento realizado em 22 periódicos nacionais na área de Ensino de Ciências, que buscou identificar os trabalhos mais citados como fontes de consulta ou referência, considerando os artigos que continham as palavras ciência, tecnologia e sociedade, juntas ou separadas. Os artigos encontrados foram modelados como uma rede de citações. Foram identificados 88 trabalhos, dos quais resultaram 394 fontes e listados os 13 trabalhos mais citados. Os resultados permitem inferir que: há predominância de autores nacionais como fonte de pesquisa dos trabalhos publicados nos principais periódicos; não estão presentes autores dos primeiros textos e trabalhos referidos na área; e que não é possível perceber a interdisciplinaridade e a contextualização características da área CTS. Resultados preliminares confirmam a necessidade de se conhecer quais as fontes de que se utilizam os autores dos principais trabalhos que servem de base para a produção CTS no Brasil.
\end{abstract}

Palavras-chave: Ensino de ciência e tecnologia. Revisão bibliográfica. Periódico. Revista científica. Citação. CTS. Redes sociais.

\begin{abstract}
This paper aimed to assess 22 Brazilian Science Teaching journals and to identify the most cited works used as references. We gathered all papers where the words science, technology and society have appeared either in the abstract or in the keywords. Our research considered 88 articles and 394 citations where the 13 most cited papers were obtained. A citation network was built from the selected papers. From the results, we have drawn some conclusions: there is a predominance of citations to Brazilian authors and they are the main source in most of the journals and papers analyzed in this research; it is not possible to perceive inter-disciplinarity and contextualization, two STS distinctive attributes. Our partial results also confirmed the needed to know which source the key STS Brazilian authors are using as a foundation to their own study and its impact on STS production in Brazil.

Keywords: Science and technology teaching. Periodical. Scientific magazine. Citation. Literature review. STS. Social networks.

\footnotetext{
${ }^{1}$ Programa de Pós-graduação em Ensino de Ciências, Centro Federal de Educação Tecnológica Celso Suckow da Fonseca (CEFET). Avenida Maracanã, 229, Bloco E, $5^{\circ}$ andar, Rio de Janeiro, RJ, CEP 20271-110, Brasil. $<$ alvaro.chrispino@gmail.com>

${ }^{2}$ Programa de Pós-graduação em Tecnologia, Centro Federal de Educação Tecnológica Celso Suckow da Fonseca (CEFET), Rio de Janeiro, RJ, Brasil.

${ }^{3,4,5}$ Centro Federal de Educação Tecnológica Celso Suckow da Fonseca (CEFET), Rio de Janeiro, RJ, Brasil.
} 


\section{Introdução}

Apesar dos estudos CTS (Ciência, Tecnologia e Sociedade), ou estudos sociais da ciência e da tecnologia, não serem recentes, somente em meados dos anos 1960 e início dos anos 1970 o movimento CTS começou a se manifestar nos Estados Unidos, nas grandes economias da Europa e na América Latina. Embora, nesta última, o movimento estivesse menos organizado, pôde-se identificar o que, posteriormente, foi denominado "Pensamento Latino Americano de Ciência, Tecnologia e Sociedade" (PLACTS) ${ }^{6}$. Seu início é marcado pela insatisfação de parte da comunidade acadêmica com a concepção tradicional da ciência e da tecnologia, e com as consequências desta concepção para a sociedade. Isto motivado pela observação dos latentes problemas sociais, políticos, ambientais e econômicos decorrentes do desenvolvimento científico-tecnológico sob aquele modelo. De acordo com Mitcham (1990), os estudos CTS surgem como uma reconsideração crítica do papel da ciência e da tecnologia na sociedade, tanto em relação à visão essencialista da ciência e da tecnologia como em relação à visão interdisciplinar entre as diversas áreas do conhecimento, incentivando o questionamento das certezas tidas como absolutas sobre a ciência e a tecnologia, desvelando a sua nãoneutralidade, e tomando decisões mais coerentes em relação aos problemas nos quais os conhecimentos científicos e tecnológicos estejam presentes. Ou seja, a necessidade do cidadão de conhecer os seus direitos e obrigações, de pensar por si próprio e ter uma visão mais crítica da sociedade onde vive, especialmente, a vontade de modificar a realidade para melhor.

No que se refere ao contexto sul-americano, Kreimer e Thomas (2004) - assim como Vaccarezza (2002) -, ao refletirem sobre as origens e características dos estudos sociais da ciência e da tecnologia, escrevem que

Os critérios para delimitar aquilo que 'está nos limites' deste campo não estão hoje suficientemente estabelecidos, apresentando um contorno com fronteiras difusas, em que a reivindicação de pertinência não encontra bases suficientemente compartilhadas para instalar-se de modo relativamente estável. (VACCAREZZA, 2002, p. 12)

Apesar disto, os autores afirmam que, feita a análise histórica da área, percebe-se que "se diversificaram as abordagens teórico-metodológicas e se incorporou novas temáticas" (KREIMER; THOMAS, 2004, p. 45), mesmo com a fluidez das definições e estabelecimentos de marcos que permitam melhor e maior entendimento da área interdisciplinar e contextualizada que define a área CTS, na sua gênese.

Esta dificuldade de conceituar, e mesmo de estabelecer limites para a definição, é indicada por diversos autores. Por exemplo, Membiela (2001, p. 91, tradução nossa) escreve que, sobre a definição do movimento CTS, "há muito debate e pouco consenso entre a comunidade CTS".

${ }^{6} \mathrm{O}$ PLACTS, por sua singularidade e por dirigir-se de forma mais específica à produção de políticas em Ciência e Tecnologia pela ótica CTS, deixará de ser tratado aqui, onde o foco é a área de Ensino em Ciência e Tecnologia. O tema é discutido e aprofundado por Dagnino e Thomas (2003). 
É, pois, possível perceber que as fronteiras e definições não estão claras nem para os chamados Estudos CTS nem para o Movimento CTS. A mesma dificuldade é encontrada quando estreitamos a análise para a Educação CTS. Aikenhead (2005) escreveu um artigo com curioso título, que demonstra esta dificuldade da área, 'Educação ciência-tecnologia-sociedade (CTS): uma boa ideia como queira que se chame' (tradução nossa). Neste texto, lançando mão de vários autores e obras, Aikenhead (2005) narra a história do surgimento e da evolução da educação CTS, especialmente, nos EUA, deixando clara a diversidade de abordagens e a interação entre as diversas áreas do conhecimento na construção do que conhecemos como CTS.

No Brasil, a abordagem CTS ganhou maior fôlego a partir da década de 1990, onde se percebe uma florescência de textos que abordam esta temática, oriundos, em sua esmagadora maioria, da área de ensino de ciência e tecnologia.

Por tudo isso, é possível dizer que a reunião de saberes sobre as relações CTS ainda é muito recente, possuindo abordagens e sentidos diferentes para muitos daqueles que tratam do tema. Este estudo pretende contribuir para o mapeamento do estado da arte das pesquisas e publicações realizadas no Brasil em CTS. Em um primeiro movimento, identifica, a partir de um conjunto de publicações selecionadas de periódicos brasileiros referenciados na área, os artigos que tratam do tema, e identifica em quem estes artigos se apoiam teoricamente, listando, assim, os mais citados ou referenciados na construção da área. Numa segunda fase, buscou-se identificar quem os mais citados citam, tentando, quanto possível, descer às fontes primárias que alicerçaram o desenvolvimento da área originalmente. Para identificar as redes de publicações e suas inter-relações, os dados foram analisados no programa PAJEK (BATAGELJ; MRVAR, 2011, p. 28), versão 1.19, desenvolvido para análise e visualização de grandes redes que possuam milhares ou até milhões de nós.

A proposta é identificar as origens e perfis dos trabalhos que mais influenciam a abordagem CTS em um período contemporâneo, deixando para um segundo momento - já em fase de conclusão - a apresentação dos resultados que apontam as origens teóricas dos autores mais citados atualmente, permitindo um estudo das fontes (mais) primárias que referenciam a Abordagem CTS no Brasil.

Trabalho de mesmo cunho, mas com foco diferenciado, foi realizado por Hunsche et al. (2009), com o objetivo de mapear o estado da arte relativamente à temática CTS no contexto brasileiro. O estudo buscou trabalhos on-line no período de 1998 a 2008, na Revista Brasileira de Pesquisa em Educação em Ciências, na revista Ciência \& Educação, e na revista Ensaio: pesquisa em educação em ciências. Assim, o problema de pesquisa foi enunciado como: quais têm sido os encaminhamentos dados, em termos teórico-metodológicos, ao campo CTS, no contexto brasileiro? Neste trabalho, os autores dividem os 12 artigos encontrados em três categorias: implementações, concepções e pressupostos/reflexões.

Outra pesquisa baseada em revisão bibliográfica é a realizada por Auler, Fenalti e Dalmolin (2009), que analisaram implementações de propostas didático-pedagógicas centradas na abordagem CTS, utilizando, como fontes de consulta, anais de eventos e materiais de ensino (e cadernos de formação e guias didáticos). Apesar de esta pesquisa identificar um número expressivo de trabalhos apresentados em eventos científicos na área, considerando a abrangência dos dados obtidos e intencionalidade de desdobramento, deixou-se de considerar este segmento.

Uma última pesquisa bibliográfica em torno do tema CTS teve seus resultados publicados por Abreu, Fernandes e Martins (2009). A pesquisa foi realizada em dez revistas da 
Chrispino, Á. et al.

área de Ensino de Ciências. Encontraram 23 artigos sobre CTS e CTSA e concluíram "que a produção nacional em CTS tem se preocupado tanto com situações do ensino em sala de aula e espaços não formais como também na elaboração teórica de um pensamento autônomo em relação às linhas européias e norte-americanas" (ABREU; FERNANDES; MARTINS, 2009, p. 10).

Dentre temas correlatos, mas que buscam fontes de consultas distintas, estão os de Pansera-de-Araújo et al. (2009), Mezalira (2008) e Araújo (2009). Os dois primeiros trabalhos buscam informações a partir de pesquisas em eventos científicos na área, e o último, busca detalhar Educação CTS nos grupos de pesquisa no CNPq. Estes aspectos não estão contidos aqui, bem como a pesquisa envolvendo teses e dissertações.

\section{Os estudos CTS}

O avanço da ciência e da tecnologia tem possibilitado, à humanidade, o crescente domínio (mesmo que relativo, às vezes) sobre a natureza, bem como gerado soluções e artefatos que têm sido responsáveis pelo desenvolvimento de praticamente todas as áreas de conhecimento humano. Mas este trajeto não é livre de ocorrências danosas ou, mesmo, questionáveis, pois não estamos diante de um modelo linear de desenvolvimento, que poderia supor que sempre seus resultados seriam benéficos para a sociedade. Berlinguer (1993) nos adverte que a velocidade com que se passa da pesquisa pura para a aplicada é, hoje, tão alta que a permanência, mesmo que por breve tempo, de erros ou fraudes pode provocar catástrofes.

Entender as complexas relações entre Ciência, Tecnologia e Sociedade - CTS envolve a percepção de que as afirmações simplistas do denominado relatório Bush (1945) ainda são verdadeiras para muitos, nos ambientes produtivos, acadêmicos e políticos. Para Bush (1945 apud SAREWITZ, 1996, p. 17, tradução nossa):

Os avanços na ciência, quando colocados no uso prático significam: mais trabalho, salários mais altos, horas mais curtas, colheita mais abundante, tempo mais livre para a recreação, para o estudo, para aprender a viver sem o trabalho fatigoso e enfraquecedor que tem sido a carga do homem comum do período passado. Mas, para alcançar estes objetivos[...] o fluxo do conhecimento científico novo deve ser contínuo e significativo.

Winner (1987 apud BAZZO, 2010) reforça a ideia de que muitos creem com veemência nesta equação linear desenvolvimentista, sem muitos questionamentos e críticas, vivendo o que chamou de "sonambulismo tecnológico". Ele diz que:

Grande parte destas respostas pode-se encontrar na assombrosa influência da ideia de "progresso" no pensamento social durante a era industrial. No século XX [mais ainda no século XXI] se acredita em geral que os únicos meios confiáveis para o melhoramento da condição humana provêm das novas máquinas, substâncias químicas e as mais 
A área CTS no Brasil vista como rede social: ...

diversas técnicas. Inclusive os recorrentes males sociais e do ambiente que acompanham os avanços tecnológicos raras vezes têm afetado esta fé. Ainda é um requisito prévio que a pessoa que queira postular um cargo público assegure sua confiança férrea em que existe um laço positivo entre desenvolvimento técnico e bem-estar humano e afirme que a próxima onda de inovações será nossa salvação. (WINNER, 1987 apud BAZZO, 2010, p. 21)

O que se pretende com os estudos CTS é trazer a discussão das implicações tecnocientíficas para o contexto social, buscando-se melhores meios para que a sociedade possa participar, democraticamente, na indicação dos seus rumos, e não apenas ficar a reboque das decisões tomadas na esfera dos tecnocratas ou daqueles que acreditam que a ciência e a tecnologia são neutras e destituídas de interesses e valores dos mais diversos.

\section{Redes sociais}

A definição de redes sociais está longe de conceitos unificadores. Datam da década de 1940 o desenvolvimento de conceitos estruturais que possibilitaram o estudo das relações em rede. Em sua abordagem, as inter-relações adquirem cunho mais metafórico, pois não são consideradas suas propriedades na multiplicidade das relações sociais.

Barnes (1987) foi um dos pioneiros na utilização do termo abordando padrões de fios e seus entrelaçamentos, acoplado aos conceitos das Ciências Sociais. Para ele, o estudo das redes se amplia em direção a uma análise e descrição daqueles processos sociais que envolvem conexões que transpassam os limites de grupos e categorias.

Mitchell (1996 apud SCOT'T, 2004) procura conciliar o uso metafórico e o analítico, pois ambos, isoladamente, possuem limitações. Enquanto na metáfora a noção de rede não permite a percepção de aspectos das relações sociais, a abordagem analítica limitaria a representação pessoal em linhas e nós de rede. Mitchell (1996 apud SCOTT, 2004) seria o responsável por estruturar as bases para uma pesquisa sistemática da análise das redes sociais. Com ênfase na matemática da teoria dos grafos, juntou-as com a pesquisa sociológica para poder esclarecer as propriedades estruturais da organização social.

A maneira viva como se processam as inter-relações nas redes sociais sugere uma abordagem complexa e inclusiva. Por tal, todas as nuances e possibilidades de comunicação devem ser consideradas, constituindo, assim, um ambiente dinâmico de múltiplas relações que só adquirem significado total quando se contempla sua completude. A metáfora utilizada por Elias (1994, p. 35) deixa claro que

[...] para ter uma visão mais detalhada desse tipo de inter-relação, podemos pensar no objeto de que deriva o conceito de rede: a rede de tecido. Nessa rede, muitos fios isolados ligam-se uns aos outros. No entanto, nem a totalidade da rede nem a forma assumida por cada um de seus fios podem ser compreendidas em termos de um único fio, ou mesmo de todos eles, isoladamente considerados; a rede só é 
Chrispino, Á. et al.

compreensível em termos da maneira como eles se ligam, de sua relação recíproca.

Diante da miríade de possibilidades que uma Rede Social no campo de CTS oferece, o objeto deste estudo, que é o mapeamento de uma rede de citações, vai se concentrar nos aspectos estruturais da rede, em detrimento de suas dimensões funcionais. Contudo, para as necessidades deste estudo, critérios como tamanho, densidade, textura, composição e distribuição ajudam muito mais do que aqueles qualitativos e emocionais, típicos das relações humanas. Esta abordagem também irá delimitar a medida de centralidade que será utilizada.

\section{Conceitos básicos em redes}

No desenvolvimento do trabalho, foi considerada a Teoria dos Grafos e suas ferramentas para modelar uma rede, em particular, a rede de citações em CTS. Portanto, alguns conceitos utilizados ao longo do trabalho são aqui introduzidos.

Uma rede, que pode ser modelada por um grafo, é definida como um conjunto de vértices ou atores cujas inter-relações são representadas por arcos. Essa rede é conexa se existe, no mínimo, um caminho entre quaisquer pares de vértices. Caso não exista, dizemos que a rede é desconexa e cada subconjunto conexo é definido como um componente conexo. Interessante destacar que a componente conexa com maior número de vértices é, frequentemente, denominada na literatura como componente conexa gigante da rede. Usualmente, uma rede é dita direcionada quando um sentido de fluxo é estabelecido entre os vértices. Nesse tipo de rede direcionada, há dois graus associados a um vértice: o grau de entrada e o de saída. O grau de entrada de um vértice é dado como o total de arcos incidentes a este; o grau de saída corresponde ao total de arcos que partem de um vértice. Os graus de entrada e saída de um vértice são frequentemente utilizados como medida de centralidade de um vértice da rede. A seção seguinte faz uma descrição dos conceitos de centralidade em redes e apresenta a ideia geral de três métricas de centralidade.

\section{Medidas de centralidade}

As medidas de centralidade posicionam os pontos da rede a partir de graus que indicam as posições mais centrais na malha da rede, de acordo com a finalidade da abordagem. Existem diferentes tipos de centralidade nas redes sociais, e, em algumas delas, não são os pontos com mais ligações diretas que ocupam posições mais centrais, mas aqueles que, por sua posição estratégica, têm papel de destaque na informação e comunicação.

Marteleto (2001) apresenta três medidas que exemplificam esta abordagem. A centralidade da Informação é quando a posição estratégica do ponto permite receber informações de toda a malha; a centralidade de Proximidade garante posição mais central àquele ponto que está em menor distância dos outros pontos de ligação na malha, e a centralidade 
A área CTS no Brasil vista como rede social: ...

de Intermediação, que é

[...] o potencial daqueles que servem como intermediários. Calcula o quanto um ator atua como "ponte", facilitando o fluxo de informação em uma determinada rede. Um sujeito pode não ter muitos contatos, estabelecer elos fracos, mas ter uma importância fundamental na mediação das trocas. O papel de mediador traz em si a marca do poder de controlar as informações que circulam na rede e o trajeto que elas podem percorrer. (MARTELETO, 2001, p. 79)

Não obstante todas estas possibilidades, o objeto deste estudo vai se concentrar na abordagem que considera mais central aquele ponto com maior número de contatos diretos com outros pontos, a partir da informação de seu grau de entrada correspondente no grafo. Esta abordagem simples e direta atende perfeitamente ao objetivo de se buscarem publicações/ autores mais citados, numa rede formada por relações diretas e perfeitamente quantificáveis, com o auxílio do PAJEK. Numa proposta de estudo posterior, serão tratadas outras medidas de centralidade e suas inter-relações, buscando identificar que autores, mesmo não sendo os mais citados em quantidade, servem de conexão entre os múltiplos grupos que compõem a área CTS.

\section{Rede de citações: um estudo de caso}

\section{Definição do problema abordado}

Por se tratar de um campo de estudos bastante heterogêneo e de certa forma recente, pelo menos sob a utilização do acrônimo CTS, buscou-se estabelecer quais autores serviram de base e influenciaram a produção acadêmica nacional na área. Nesta primeira fase do trabalho, o objetivo é buscar as publicações mais citadas em artigos de CTS. O próximo estudo utilizará estes resultados para buscar aqueles que servem de fonte primária para as publicações mais citadas.

\section{Metodologia}

O estudo pesquisou publicações brasileiras no período de 1996 a 2010, identificou artigos que atendiam os requisitos da pesquisa, e, após isso, restaram selecionados os seguintes periódicos: Caderno Brasileiro de Ensino de Física (Universidade Federal de Santa Catarina), Educar em Revista (Universidade Federal do Paraná), Alexandria: revista de educação em ciência e tecnologia (Universidade Federal de Santa Catarina), Avaliação: revista de avaliação da educação superior (Universidade Estadual de Campinas), Biodiversidade (Universidade Federal de Mato Grosso), Revista Brasileira de Ciência, Tecnologia e Sociedade (Universidade Federal de São Carlos), Revista Brasileira de Ensino de Ciência e Tecnologia (Universidade Tecnológica Federal do Paraná), Revista Brasileira de Ensino de Física (Sociedade Brasileira de Física), Revista Brasileira de Pesquisa em Educação em Ciências (Associação Brasileira de Pesquisa em Educação em Ciências), Ciência \& Educação (Universidade Estadual Paulista), 
Chrispino, Á. et al.

Ciências e Cognição (Universidade Federal do Rio de Janeiro), Ciência \& Ensino (Universidade Estadual de Campinas), Ciência em Tela (Universidade Federal do Rio de Janeiro), Revista Científica da UFPA (Universidade Federal do Pará), Educação \& Realidade (Universidade Federal do Rio Grande do Sul), Ensaio: pesquisa em educação em ciências (Universidade Federal de Minas Gerais), Experiências em Ensino de Ciências (Universidade Federal do Rio Grande do Sul), Investigações em Ensino de Ciências (Universidade Federal do Rio Grande do Sul), Pesquisa em Educação Ambiental (Universidade de São Paulo), Química Nova (Sociedade Brasileira de Química), Química Nova na Escola (Sociedade Brasileira de Química) e Revista Tecnologia e Sociedade (Universidade Tecnológica Federal do Paraná).

Deixou-se de considerar, como fonte de pesquisa para este trabalho, as dissertações, as teses e os trabalhos publicados em eventos científicos da área, apesar do expressivo número encontrado. Estas fontes podem indicar material de pesquisa para futuras publicações a partir da mesma ferramenta de análise de redes sociais.

A busca partiu das palavras-chave ciência, tecnologia e sociedade, separadas ou juntas. Após a catalogação, foi realizada leitura de cada artigo a fim de garantir que o mesmo se referia ao tema que motiva a pesquisa. Após leitura individual destes artigos, fez-se uma segunda filtragem, deixando apenas aqueles que tratavam efetivamente da tríade CTS. Assim, resultaram nos 88 artigos (Anexo A), e estes forneceram um total de 394 fontes bibliográficas.

Para obter as publicações mais citadas em CTS, utilizou-se o software PAJEK, que é um programa livre para Windows, voltado à análise e visualização de grandes redes com alguns milhares ou, mesmo, milhões de vértices (conjunto de pontos). Sua principal característica é decompor a rede em estruturas menores, oferecendo ferramentas de análise de estruturas, tais como: redes de colaboração, molécula orgânica em química, receptor proteico, redes de interação, genealogias, redes de Internet, redes de citação, redes de difusão (AIDS, notícias, inovações), mineração de dados, entre outras.

O início do trabalho foi marcado pela construção da rede de citações a partir das 394 fontes bibliográficas. Nesta rede de citações, cada vértice corresponde a uma fonte bibliográfica, e os arcos representam as inter-relações entre as fontes bibliográficas. Dessa forma, se uma fonte bibliográfica $f_{1}$ cita a fonte bibliográfica $f_{2}$, então há um arco conectando os vértices $f_{1}$ e $f_{2}$ no sentido $f_{1} \rightarrow f_{2}$ na rede. A partir dessa modelagem, foi possível obter uma rede direcionada com 394 vértices e 595 arcos.

A segunda etapa dessa representação contemplou a inclusão da rede de citações no programa PAJEK, o que resultou no gráfico da Figura 1. A principal finalidade na utilização do PAJEK é calcular de forma automática os valores de centralidade de todos os atores da rede. Os resultados computacionais obtidos estão descritos na seção de resultados obtidos.

\section{Resultados obtidos}

Nessa seção, estão descritos os passos utilizados no PAJEK para a identificação dos vértices com maior grau de entrada, ou seja, com o maior número de citações no período de 1996 a 2010.

Para selecionar a maior componente conexa da nossa rede, ou seja, o maior número possível de fontes bibliográficas que estavam de alguma forma conectadas entre si, utilizou-se as funções: Net / Components / Weak com tamanho mínimo 10, Operations / Extract from 
A área CTS no Brasil vista como rede social: ...

Network / Partition, Draw / Draw-Partition e, por fim, Layout / Energy / Kamada-Kawai / Fix First and Last. Das 394 fontes bibliográficas que compõem a rede, obteve-se uma componente com 378 conectadas, ou seja, foram excluídas as fontes bibliográficas que não estavam conectadas à maior componente conexa representada na Figura 2.

Figura 1. Grafo direcionado gerado pelo PAJEK na fase 1.

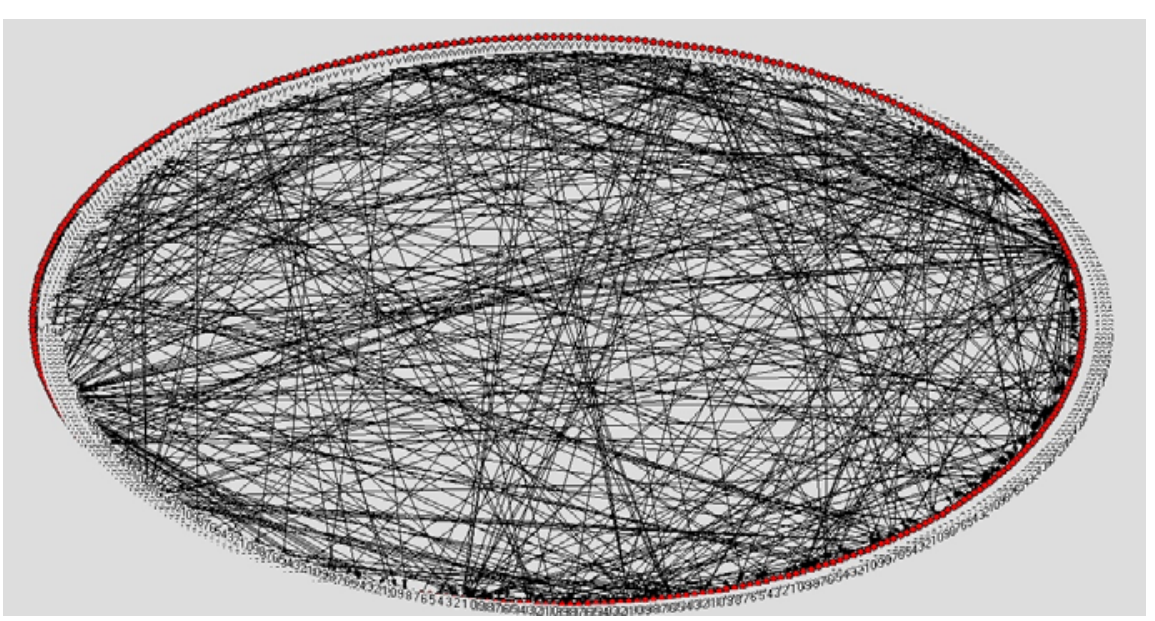

Fonte: Elaborado pelos autores.

Figura 2. Maior componente conexa da $1^{\mathrm{a}}$ fase.

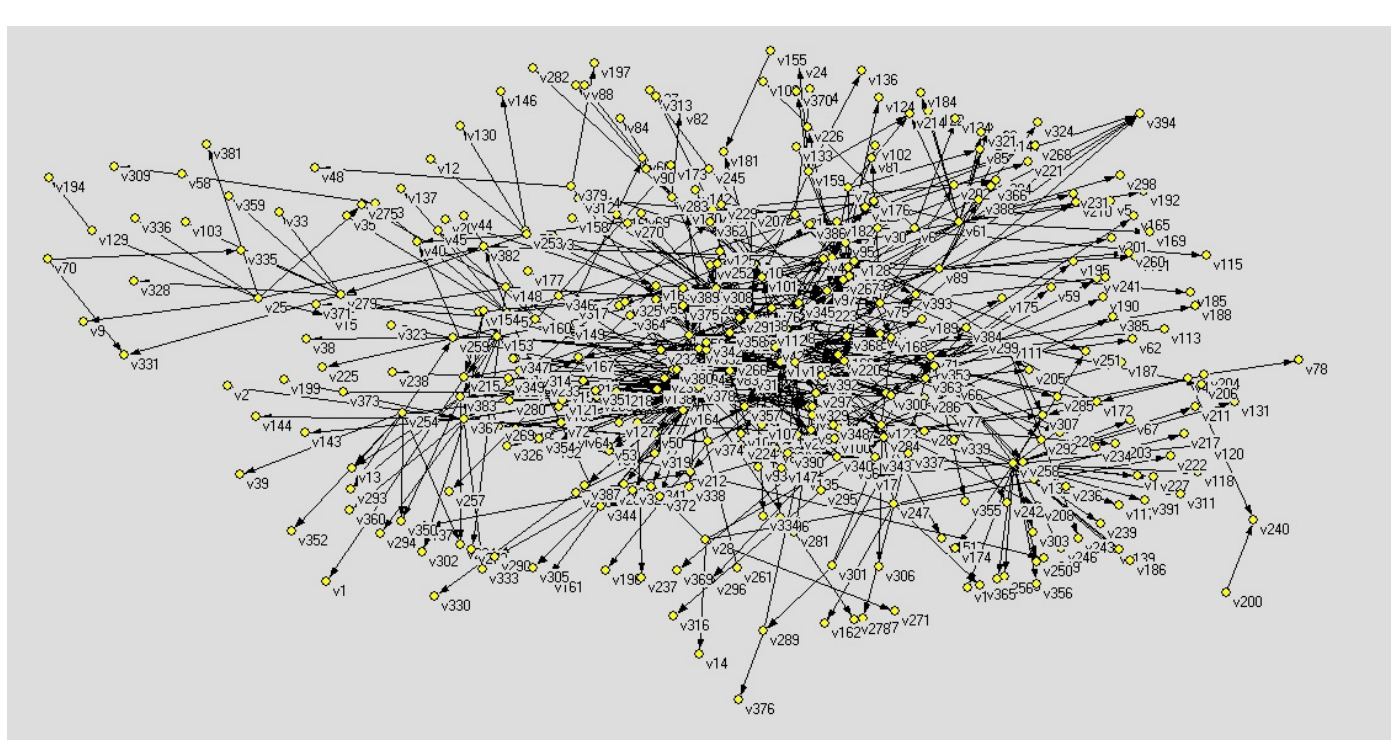

Fonte: Elaborado pelos autores. 
Chrispino, Á. et al.

Utilizou-se, então, a função Net/Partitions/Degree/Input, que é usada para particionar e calcular o grau de entrada de cada vértice. Em seguida, utilizaram-se as funções Draw/DrawPartition e Layout/Circular/Using Partition, para separar a partição por cores e, desta forma, visualizar os 13 trabalhos mais citados em CTS, que correspondem aos vértices 41, 71, 97, 98, 101, 168, 220, 223, 263, 266, 308, 351 e 378, conforme pode ser visto na Figura 3.

Figura 3. Grafo particionado por cor de acordo com o grau de entrada do vértice.

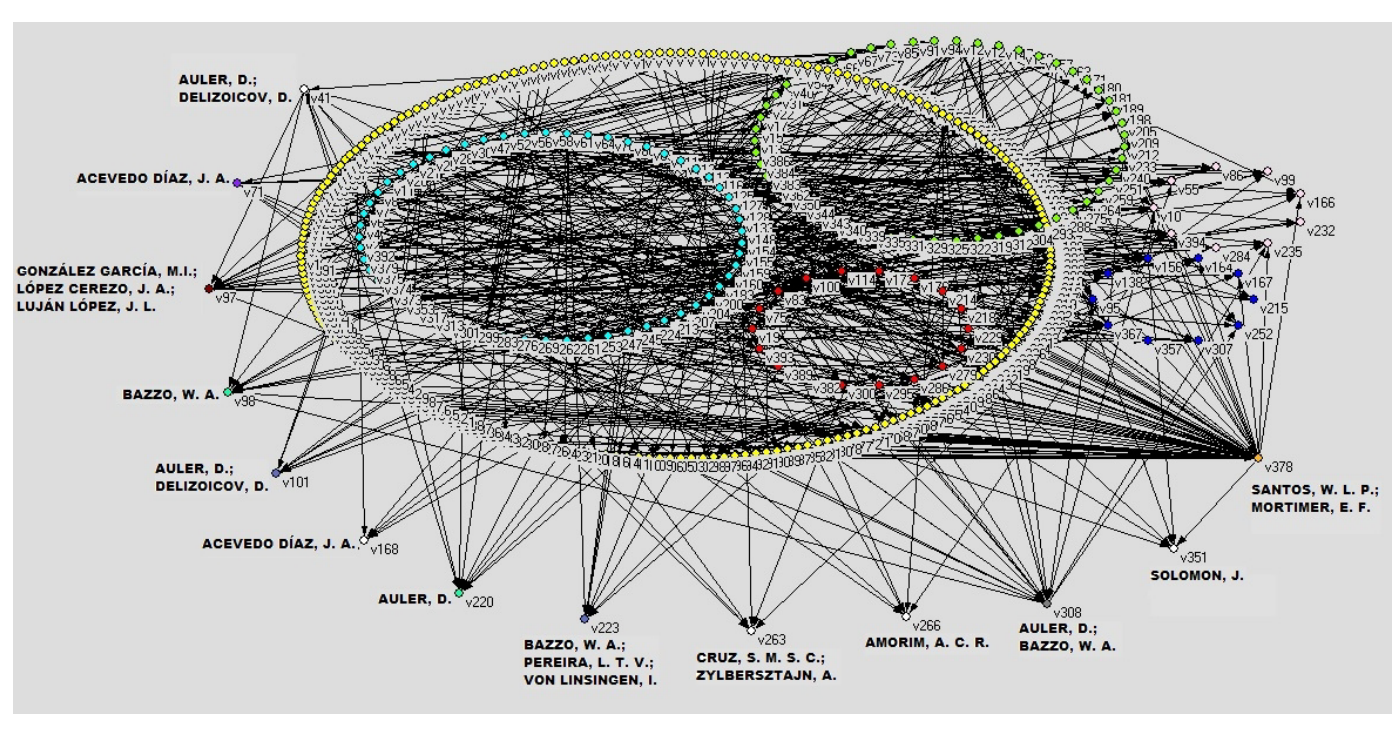

Fonte: Elaborado pelos autores.

Note-se que vértices de cores iguais possuem o mesmo grau de entrada. Estes vértices correspondem aos trabalhos listados abaixo, ordenados do mais citado para o menos citado entre os 13:

1. SANTOS, W. L. P.; MORTIMER, E. F. Uma análise de pressupostos teóricos da abordagem.C-T-S (Ciência-Tecnologia-Sociedade) no contexto da educação brasileira. Ensaio: pesquisa em educação em ciências, Belo Horizonte, v. 2, n. 2, p. 105-115, 2002.

2. GONZÁLEZ GARCÍA, M. I.; LÓPEZ CEREZO, J. A.; LUJÁN LÓPEZ, J. L. Ciencia, tecnología y sociedad: una introducción al estudio social de la ciencia y la tecnología. Madrid: Tecnos, 1996. 
A área CTS no Brasil vista como rede social: ...

3. AULER, D.; BAZZO, W. A. Reflexões para a implementação do movimento CTS no contexto educacional brasileiro. Ciência \& Educação, Bauru, v. 7, n. 1, p. 1-13, 2001.

4. AULER, D. Interações entre ciência-tecnologia-sociedade no contexto da formação de professores de ciências. 2002. 248 f. Tese. (Doutorado em Educação Científica e Tecnológica) - Universidade Federal de Santa Catarina, Florianópolis, 2002.

5. BAZZO, W. A. Ciência, tecnologia e sociedade e o contexto da educação tecnológica. Florianópolis: Ed. da UFSC, 1998.

6. BAZZO, W. A.; VON LINSINGEN, I.; PEREIRA, L. T. V. (Ed.). Introdução aos estudos CTS (ciência, tecnologia e sociedade). Madrid: Organização dos Estados Iberoamericanos para a Educação, a Ciência e a Cultura, 2003. (Cadernos de iberoamerica).

7. AULER, D.; DELIZOICOV, D. Ciência-tecnologia-sociedade: relações estabelecidas por professores de ciências. Revista Electrónica de Enseñanza de las Ciencias, Vigo, v. 5, n. 2, p. 337-355, 2006.

8. ACEVEDO DÍAZ, J. A. Cambiando la práctica docente en la enseñanza de las ciencias a través de CTS. Borrador, Huelva, v.13, p. 26-30, 1996.

9. AMORIM, A. C. R. O ensino de biologia e as relações entre ciência / tecnologia / sociedade: o que dizem os professores e o currículo do ensino médio? In: ENCONTRO PERSPECTIVAS DO ENSINO DE BIOLOGIA, 6., 1997, São Paulo. Anais... São Paulo: USP, 1997. p. 74-77.

10. CRUZ, S. M. S. C.; ZYLBERSZTAJN, A. O enfoque ciência, tecnologia e sociedade e a aprendizagem centrada em eventos. In: PIETROCOLA, M. (Org.). Ensino de física: conteúdo e epistemologia numa concepção integradora. Florianópolis: Ed. da UFSC, 2001. p. 171-196.

11. SOLOMON, J. Teaching science, technology and society. Buckingham: Open University Press, 1993.

12. ACEVEDO DÍAZ, J. A. Educación tecnológica desde una perspectiva CTS: una breve revisión del tema. Alambique: didáctica de las ciencias experimentales, Barcelona, v. 2, n. 3, p. 75-84, 1995.

13. AULER, D.; DELIZOICOV, D. Alfabetização científico-tecnológica para quê? Ensaio: pesquisa em educação em ciências, Belo Horiozonte, v. 3, n. 1, p. 105-115, 2001.

Esses dados foram gerados pelo PAJEK por meio de um relatório obtido através da função Info/Vector, conforme mostra a Figura 4.

Esse relatório apresenta os valores normalizados dos graus de entrada da partição, que é dado pela divisão do grau de entrada do vértice por (n-1), onde $n$ corresponde à dimensão da rede, ou seja, o número total de vértices da rede. Multiplicando esse resultado por 100, obtemos a percentagem de centralidade máxima. Esse relatório fornece, ainda, outras informações como: a dimensão da rede, o maior e o menor valor da normalização dos vértices, o somatório da normalização de todos os vértices da rede, a média aritmética, a mediana e o desvio padrão da rede, e, por fim, os valores dos vetores, a frequência e a frequência acumulada. De maneira similar, obteve-se um relatório com os graus de entrada dos treze mais citados na rede pela função Info/Partition, como podemos ver na Figura 5. 
Chrispino, Á. et al.

Figura 4. Os 13 trabalhos mais citados.

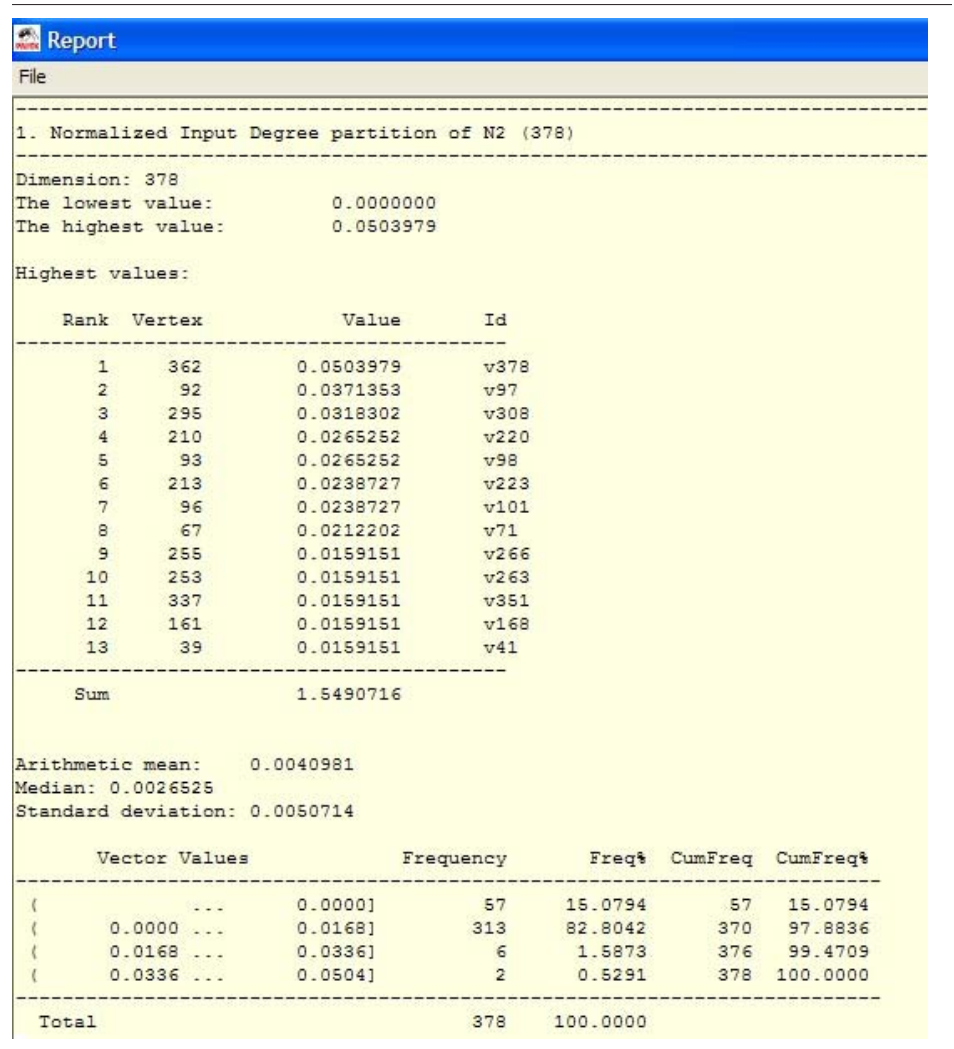

Fonte: Elaborado pelos autores.

O relatório da Figura 5 é similar ao anterior e também fornece uma ordenação não crescente dos vértices de acordo com o seu grau de entrada, porém exibe explicitamente o grau (cluster) dos treze vértices mais centrais da rede. Outras informações interessantes são ainda fornecidas, tais como: a dimensão da rede, o maior e o menor grau da rede, e a frequência de distribuição destes graus.

\section{Análise dos resultados e muitas questões}

Feito o levantamento sobre os artigos que continham as palavras-chave ciência, tecnologia e sociedade, separadas ou juntas, em 22 periódicos, no período entre 1996 e 2010, foi possível selecionar 88 artigos, e estes forneceram um total de 394 fontes bibliográficas. Aplicadas as informações ao software PAJEK, este elencou aqueles trabalhos mais citados nos artigos selecionados, oferecendo, ainda, uma visualização sobre como se relacionam os trabalhos com as diversas fontes bibliográficas. 
A área CTS no Brasil vista como rede social: ...

Figura 5. Os graus de entrada dos 13 mais citados.

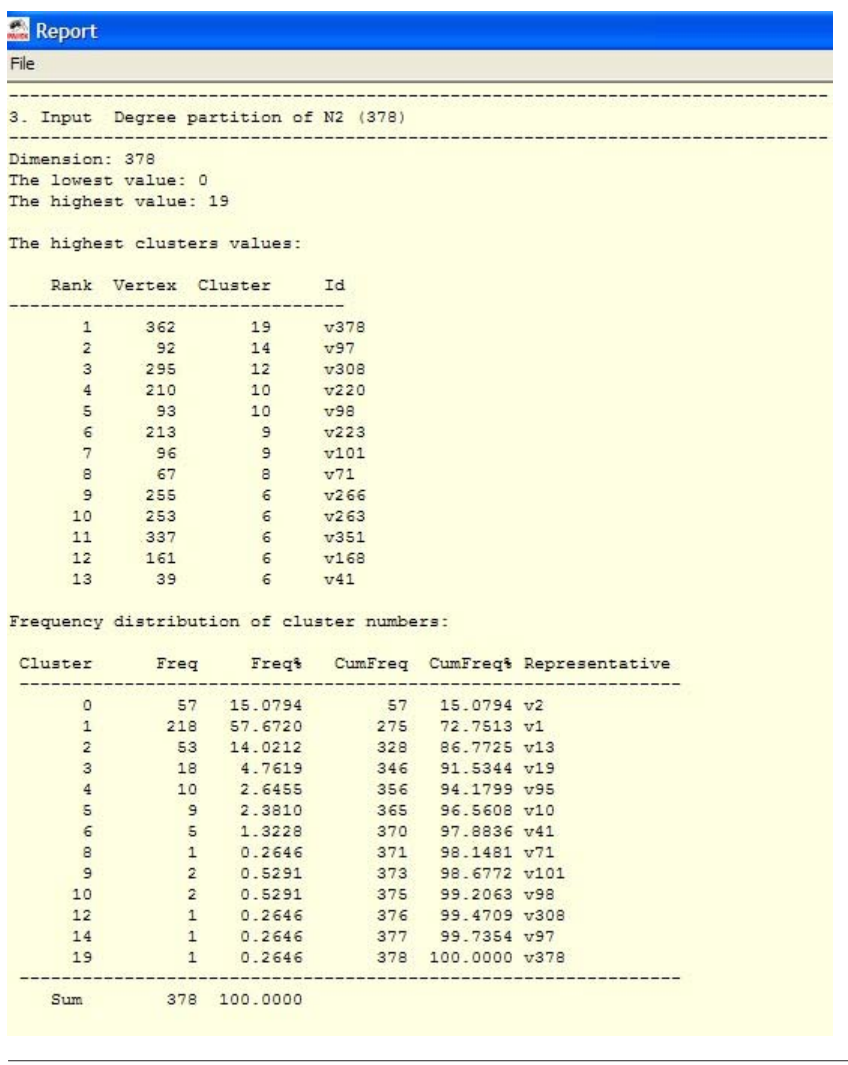

Fonte: Elaborado pelos autores.

Os 13 trabalhos mais citados resultantes da pesquisa podem ser encarados como leitura obrigatória para entendimento do que seja e o que produz a área. É o ponto comum, é o consenso, se não construído intencionalmente, certamente estabelecido pela tradição.

Resta agora buscar uma classificação que permita alguma reflexão que resulte em contribuição à área CTS, visto que, segundo Redorta (2004, p. 95), “[...] classificar é uma forma de dar sentido. A classificação costuma ser hierárquica e permite estabelecer relações de pertencimento. Ao classificar definimos, e ao definir, tomamos uma decisão a respeito da essência de algo".

Quando o resultado obtido é comparado com os trabalhos que se propõem a classificar, de alguma forma, a produção na área (AULER; FENALTI; DALMOLIN, 2009; HUNSCHE et al., 2009; PANSERA-DE-ARAÚJO et al., 2009), é possível perceber que:

- Dos 13 trabalhos aqui identificados, três estão listados na categorização proposta por Hunche et al. (2009): Auler e Bazzo (2001), Auler e Delizoicov (2001) e Santos e Mortimer (2000); 
Chrispino, Á. et al.

- Dos oito autores indicados como os mais citados nos artigos que compõem a pesquisa de Abreu, Fernandes e Martins (2009), os cinco brasileiros (Auler, Bazzo, Santos, Mortimer e Delizoicov) são citados entre os 13 trabalhos desta pesquisa, e, dos três estrangeiros (Aikenhead, Acevedo Díaz e Cachapuz), um deles é encontrado em nossa pesquisa;

- Dos 18 autores (isolados ou em coautoria) indicados como os mais citados em trabalhos apresentados em evento por Pansera-de-Araújo et al. (2009), somente Cruz e Zylbersztajn (2001), citados aqui na lista de 13 trabalhos, não aparecem na lista dos autores.

Adicionalmente, é possível dizer sobre os 13 trabalhos mais citados:

1. Sobre os trabalhos:

a) Anos de produção: 1993 (um), 1995 (um), 1996 (dois), 1997 (um), 1998 (um), 2001 (3), 2002 (dois), 2003 (um) e 2006 (um);

b) Nacionalidade dos autores (por trabalho): brasileiros (nove) e estrangeiros (quatro);

c) Formas de apresentação: artigos em periódicos (seis), livros (quatro), capítulo de livros (dois) e teses/dissertações (um).

i. Dos artigos (seis): publicados em periódicos nacionais (três) e em periódicos estrangeiros (três).

ii. Dos livros (quatro): publicados no Brasil (um), publicados no exterior (dois) e publicado no exterior com autores nacionais (um).

iii. Dos capítulos de livros (dois): publicados no Brasil (dois).

iv. Das teses/dissertações (um): estudos realizados no Brasil (um).

2. Sobre os autores:

a) Os 13 trabalhos totalizam 22 autores, com repetição, e 15 autores não repetidos, sendo que, destes 15 , dez são brasileiros e cinco são estrangeiros;

b) Dos cinco autores estrangeiros, um é americano e quatro são iberoamericanos;

c) Dos 13 trabalhos listados, Auler participa de quatro; Bazzo de três, Delizoicov e Acevedo Díaz de dois cada;

d) Os dez autores brasileiros estão distribuídos em cinco instituições de ensino:

i. Universidade Federal de Santa Catarina (UFSC): Bazzo, Von Linsingen, Pereira, Delizoicov, Zylbersztajn e Cruz;

ii. Universidade Federal de Santa Maria (UFSM): Auler;

iii. Universidade Estadual de Campinas (Unicamp): Amorim;

iv. Universidade de Brasília (UnB): Santos;

v. Universidade Federal de Minas Gerais (UFMG): Mortimer.

e) A pesquisa de Araújo (2009) identificou trinta grupos de pesquisa em torno do tema CTS, sendo que quatro deles na UFSC, quatro na Unicamp. As demais instituições encontradas nesta pesquisa (UFSM, UnB e UFMG) não foram identificadas como possuidoras de grupos de pesquisa CTS.

Retomando Aikenhead (2005, p. 117-118), é possível recolher a ideia de que a “evolução CTS dentro da ciência escolar é uma complexa história de desenvolvimento profissional e intelectual dos educadores em ciência". O autor afirma que cada país tem, por conta desse princípio, sua própria história, apresentando como exemplos, que simplificamos aqui, o Canadá e Israel, onde o ambiente foi enfatizado a ponto de se reunir a letra A (de Ambiente) a CTS, criando o CTSA. Nos Países Baixos, o Projeto de Desenvolvimento Curricular em Física 
A área CTS no Brasil vista como rede social: ...

(PLON) cresceu ao abraçar a educação ambiental, mas, ao mesmo tempo, se implantava nas escolas secundárias e nos cursos superiores, realizando pesquisas importantes sempre com a participação de estudantes. O projeto PLON influenciou unidades CTS similares na Austrália e no Canadá. "Na Inglaterra, foram desenvolvidos projetos e planos de estudos sobre o estado da arte. Eles inspiraram e guiaram os educadores em ciência de todo o mundo" (AIKENHEAD, 2005, p. 117). Na Austrália, percebe-se um vínculo com a tecnologia industrial em alguns projetos, além dos cursos CTS chamados convencionais. Na Bélgica, com Gerard Fouréz, surge a tendência de agregar a ética a CTS, sendo importante a contribuição da revista 'Sciences Technologies Ethique Societé', da Universidade de Namur. Na Itália, CTS se desenvolveu aproximando assuntos sociais de estudos cientificamente mais orientados. A Espanha, com Manassero Mas, Vázquez Alonso e Acevedo Díaz, tem abordado CTS a partir de uma perspectiva avaliativa. A história do Japão consiste em educadores em ciência que, mesmo influenciados por projetos ingleses e americanos, desenvolveram sua visão de CTS a partir de consideráveis investigações (AIKENHEAD, 2005).

A primeira questão que se pode levantar a partir dos resultados e das reflexões de Aikenhead (2005) é se os autores citados em seu histórico artigo estão na lista de obras mais referenciadas. A resposta é que, da longa e variada lista apresentada no subitem evolução CTS, somente Solomon e Acevedo Díaz aparecem na lista de Aikenhead e em nossa pesquisa.

A segunda questão que se pode elencar, após identificar os treze trabalhos mais citados na área CTS do Brasil, é se é possível traçar o perfil da área a ponto de completar a narrativa de Aikenhead (2005) dizendo, por exemplo: 'O Brasil apresenta sua visão CTS que é...'

Outras questões podem ser transpostas de Aikenhead (2005, p. 120) na visão de futuro de CTS e aplicadas ao Brasil. Essas possíveis questões, a partir do artigo que "buscou traçar a complexidade de subculturas, lealdades, interesses pessoais e conceitos associados com o surgimento, evolução e reformulação da ciência CTS nas escolas" (AIKENHEAD, 2005, p. 120) são: o que subjaz a esta complexidade? Os educadores CTS parecem reunir-se ao redor de diversos interesses e metas. Este paradoxo demanda uma explicação. Eles coincidem com a necessidade de reformar a ciência escolar [...], e eles valoram termos como humanismo, dando relevância a atividades centradas no estudante. Que força aglutinadora reúne os educadores em ciência dentro do movimento CTS?

Há 25 anos, Alonso, Ayestarán e Ursúa (1996) coordenaram a publicação intitulada 'Para comprender ciência, tecnologia y sociedad', com prólogo de Carl Mitcham, epílogo de Wiebe E. Bijker, além de capítulos de Leonard J. Waks, Paul Durbin e de outros especialistas europeus, especialmente espanhóis. A tônica do trabalho foi a importância da interdisciplinaridade da área CTS, onde se enfatizava a necessidade de se considerarem abordagens próximas ao que já se tem hoje como história da ciência e da tecnologia, filosofia da ciência e da tecnologia e sociologia da ciência e da tecnologia. Além disso, pregavam, para melhor compreensão da área CTS, a necessidade de disciplinas como: economia da ciência e da tecnologia e política de ciência e tecnologia. Por tal, o livro é estruturado em visões desde a história, a filosofia, a sociologia, a economia e os aspectos metodológicos próprios. A observação da lista dos mais citados na área CTS brasileira demonstra que estes pressupostos também não se repetem no Brasil. Observa-se que as citações são, na sua maioria, de fontes secundárias, tanto se consideradas as citações de Aikenhead (2005) quanto as encontradas em Alonso, Ayestarán e Ursúa (1996). 


\section{Conclusões e consequências}

A pesquisa cujos resultados se apresentam é preliminar. Na verdade, buscam-se conhecer, em um primeiro momento, os trabalhos mais citados na Educação CTS, a partir dos periódicos especializados. Com isso, é possível modelar onde professores e alunos da área de ensino de ciência e tecnologia buscam, primeiramente, as informações que utilizam em suas pesquisas e artigos. Cumpriu-se esta etapa. Por meio do PAJEK e a partir de pesquisa exaustiva, foi possível elencar os treze trabalhos mais citados na área.

Os resultados anteriormente detalhados permitem uma análise crítica mais densa: não são citados, em geral, autores tidos como fundadores da área, de acordo com alguns trabalhos que se dedicam a apresentar a história CTS. Certamente, por conta da qualidade dos trabalhos nacionais que apresentam a área e sintetizam seus fundamentos, dando indicações seguras sobre sua responsabilidade na modelagem da área de CTS em ensino de ciências no Brasil. É possível imaginar que (1) a barreira do idioma e (2) a inexistência de exemplares disponíveis também dificultem esta busca pelas fontes primárias, em geral não disponíveis em meio digital.

É necessário também considerar-se que o resultado da pesquisa parece enfatizar a endogenia na área de ensino de ciência e tecnologia, por mais que se defenda a ideia de que a área CTS é interdisciplinar, necessitando, por princípio fundante, de conhecimentos advindos da filosofia, da sociologia, da história, da economia, da política, da cultura, entre outros.

Para Acevedo Díaz, Vázquez Alonso e Manassero Mas (2001, p. 2, tradução nossa), no momento atual,

[...] emerge a educação CTS (Ciência, Tecnologia e Sociedade) como inovação do currículo escolar (Acevedo, 1996a, 1997a, Vázquez, 1999), de caráter geral, que proporciona propostas de alfabetização em ciência e tecnologia (Science and Technology Literacy, STL) para todas as pessoas (Science and Technology for All, STA), uma determinada visão centrada na formação de atitudes, valores e normas de comportamento a respeito da intervenção da ciência e da tecnologia na sociedade (e vice-versa) com o fim de exercer responsavelmente como cidadãos e poder tomar decisões racionais e democráticas na sociedade civil. Desde este ponto de vista, CTS é uma opção educativa transversal (Acevedo, 1996b), que prioriza sobretudo os conteúdos atitudinais (cognitivos, afetivos e valorativos) e axiológicos (valores e normas).

Desde a perspectiva da dimensão cognitiva atitudinal, a educação CTS pretende também uma melhor compreensão da ciência e da tecnologia em seu contexto social, incidindo nas inter-relações entre os desenvolvimentos científico e tecnológico e os processos sociais. Assim, os estudantes deverão adquirir durante sua escolarização algumas capacidades para ajudá-los a interpretar, pelo menos de forma geral, questões controvertidas relacionadas com os impactos sociais da ciência e da tecnologia e com a qualidade das condições de vida de uma sociedade cada vez mais impregnada de ciência e, sobre tudo, de tecnologia. 
A área CTS no Brasil vista como rede social: ...

Essa descrição da Educação CTS voltada para o ensino de ciência e tecnologia parece depreender a necessidade de, novamente, se apresentarem os conhecimentos CTS a partir de uma visão interdisciplinar e contextualizada. Para isso, é preciso superar a possível restrição de produção da área de ensino, a fim de buscar, nas áreas fundantes de CTS - filosofia, sociologia, história, cultura, economia, política, meio ambiente etc. -, as ideias-chave que permitirão formar professores e alunos, estruturar materiais e aprimorar as análises críticas dos fatos tecnocientíficos de alto impacto social por diversos ângulos.

Por tal, torna-se necessário - além de conhecer os trabalhos mais citados da área, cujo estudo por si só já representaria uma boa formação em CTS, considerando serem estes importantes fontes para a produção brasileira -, conhecer onde os autores destes principais trabalhos buscaram inspiração e fundamentos e, a partir disso, desenhar que áreas estão - ou não - representadas no CTS brasileiro. Em outras palavras, onde reside nosso fundamento e que lacunas estruturais existem na base do conhecimento que edifica a área CTS no ensino de ciência e tecnologia do Brasil.

Com este trabalho é possível conhecer o que se pode estudar para dominar a 'média' dos conhecimentos. Os treze trabalhos representam o conhecimento acumulado na área de CTS no ensino de ciências, e isso é confirmado pelo fato de os trabalhos e/ou seus autores serem citados em outras pesquisas com metodologias ou recortes diferentes. Logo, um curso de CTS no ensino de ciências no Brasil não deve prescindir destas fontes e/ou destes autores, para ficar na média do interesse e possibilidades da área.

Sabendo onde estudam ou estudaram os principais autores referenciados, é possível saber 'de onde viemos', e, por isso, será possível saber o que precisamos fazer para irmos para onde decidirmos ser necessário, a fim de consolidarmos a Educação CTS no ensino de ciência e tecnologia. Isto é, consolidarmos os fundamentos da área CTS no ensino de ciências e, sobretudo, discutirmos as políticas que conformam ou conformarão a área. Eis o próximo passo.

\section{Referências}

ABREU, T. B.; FERNANDES, J. P.; MARTINS, I. Uma análise qualitativa e quantitativa da produção cientifica sobre CTS (ciência, tecnologia e sociedade) em periódicos da área de ensino de ciências no Brasil. In: ENCONTRO NACIONAL DE PESQUISA EM EDUCAÇÃO EM CIÊNCIAS, 7., 2009, Florianópolis. Anais... Florianópolis: ABRAPEC, 2009. Disponível em: <http://www.posgrad.fae.ufmg.br/posgrad/viienpec/pdfs/852.pdf>. Acesso em: 09 maio 2011.

ACEVEDO DÍAZ, J. A.; VÁZQUEZ ALONSO, A.; MANASSERO MAS, M. A. El movimiento ciencia-tecnología-sociedad y la enseñanza de las ciencias. In: MANASSERO MAS, M. A.; VÁZQUEZ ALONSO, A.; ACEVEDO DÍAZ, J. A. Avaluació dels temes de ciència, tecnologia i societat. Palma de Mallorca: Conselleria d'Educació i Cultura del Govern de les Illes Ballears, 2001. Disponível em: <http://www.oei.es/salactsi/ acevedo13.htm>. Acesso em: 05 maio 2008. 
Chrispino, Á. et al.

AIKENHEAD, G. Educación ciencia-tecnología-sociedad (CTS): una buena idea como quiera que se le llame. Educación Química, México, v. 16, n. 2, p. 304-315, 2005.

Disponível em: < http://garritz.com/andoni_garritz_ruiz/documentos/ciencia_sociedad/ Aikenhead $\% 20$ 'a $\% 20$ rose $\% 20$ by $\% 20$ any $\% 20$ other $\% 20$ name $\% 20 \mathrm{EQ}^{\circ} \% 202005$.pdf >. Acesso em: 03 abr. 2013.

ALONSO, A.; AYESTARÁN, I.; URSÚA, N. Para comprender ciencia, tecnología y sociedad. Estella: Verbo Divino, 1996.

ARAÚJO, R. F. Os grupos de pesquisa em ciência, tecnologia e sociedade no Brasil. Revista Brasileira de Ciência, Tecnologia e Sociedade, São Carlos, v. 1, n. 1, p. 81-97, 2009.

AULER, D.; FENALTI, V. S.; DALMOLIN, A. M. T. Abordagem temática: natureza dos temas em Freire e no enfoque CTS. Alexandria: revista de educação em ciência e tecnologia, Florianópolis, v. 2, n. 1, p. 67-84, 2009.

BARNES. J. A. Redes sociais e processo político. In: FELDMAN-BIANCO, B. (Org.). Antropologia das sociedades contemporâneas: métodos. São Paulo: Global, 1987. p. 159-193.

BATAGELJ, V.; MRVAR, A. Program for analysis and visualization of large networks: reference manual. Ljubljana, 2011. Disponível em: <http://vlado.fmf.uni-lj.si/pub/ networks/pajek/doc/pajekman.pdf >. Acesso em: 03 abr. 2013.

BAZZO, W.A. Ciência, tecnologia e sociedade e o contexto da educação tecnológica. Florianópolis: Ed. da UFSC, 2010.

BERLINGUER, G. Questões de vida: ética, ciência e saúde. São Paulo: Hucitec, 1993.

BUSH, V. Science: the endless frontier - a report to the president. Washington: United States Government Printing Office, 1945.

DAGNINO, R.; THOMAS, H. (Org.). Ciência, tecnologia e sociedade: uma reflexão latino-americana. Taubaté: Cabral Editora e Livraria, 2003.

ELIAS, N. A sociedade dos indivíduos. Rio de Janeiro: Jorge Zahar, 1994.

HUNSCHE, S. et al. O enfoque CTS no contexto brasileiro: caracterização segundo periódicos da área de educação em ciências. In: ENCONTRO NACIONAL DE PESQUISA EM EDUCAÇÃO EM CIÊNCIAS, 7., 2009, Florianópolis. Anais... Florianópolis: ABRAPEC, 2009. Disponível em: < http://posgrad.fae.ufmg.br/posgrad/ viienpec/pdfs/408.pdf>. Acesso em: 02 maio 2011.

KREIMER, P.; THOMAS, H. Un poco de reflexividad o ¿de dónde venimos?: estudios sociales de la ciencia y la tecnologia en América Latina. In: KREIMER, P. et al. (Ed.). Producción y uso social de conocimientos: estudios de sociología de la ciencia y la tecnología en América Latina. Bernal: Universidad Nacional de Quilmes, 2004. p. 11-90.

MARTELETO, R. M. Análise de redes sociais: aplicação nos estudos de transferência da informação. Ciência da Informação, Brasilia, v. 30, n. 1, p. 71-81, 2001. 
A área CTS no Brasil vista como rede social: ...

MEMBIELA, P. Una revisión del movimento CTS en la enseñanza de las ciencias. In: MEMBIELA, P. (ed.). Enseñanza de las ciencias desde la perspectiva ciencia-tecnología-sociedad: formacion científica para la ciudadanía. Madrid: Narcea, 2001. p. 91-103.

MEZALIRA, S. M. Enfoque CTS no ensino de ciências naturais a partir de publicações em eventos científicos no Brasil. 2008. 116 f. Dissertação (Mestrado em Educação nas Ciências) - Universidade Regional do Noroeste do Estado do Rio Grande do Sul, Ijuí, 2008.

MITCHAM, C. En busca de una nueva relacion entre ciencia, tecnologia y sociedad. In: MEDINA, M.; SANMARTÍN, J. (Ed.). Ciencia, tecnología y sociedad: estudios interdisciplinares en la universidad, en la educación y en la gestión política y social. Barcelona: Anthropos, 1990. p. 11-19.

PANSERA-DE-ARAÚJO, M. C. et al. Enfoque CTS na pesquisa em educação em ciências: extensão e disseminação. Revista Brasileira de Pesquisa em Educação em Ciências, São Paulo, v. 9, n. 3, p. 1-21, 2009. Disponível em: < http:// revistas.if.usp.br/rbpec/article/ download/22/21>. Acesso em: 03 maio 2011.

REDORTA, J. Cómo analizar los conflictos: la tipologia de conflictos como herramienta de mediación. Barcelona: Paidós Ibérica, 2004.

SAREWITZ, D. Frontiers of illusion: science, technology and problems of progress.

Philadelphia: Temple University Press, 1996.

SCOTT, J. Social network analysis: a handbook. [S.l: s.n.], 2004. Disponível em:

<http://www.analytictech.com/mb119/tableof.htm>. Acesso em: 08 dez. 2010.

VACCAREZZA, L. S. Ciência, tecnologia e sociedade: o estado da arte na America Latina. In: SANTOS, L. W. et al. (Org.). Ciência, tecnologia e sociedade: o desafio da interação. Londrina: Instituto Agronômico do Paraná, 2002. p. 43-77. 
Chrispino, Á. et al.

Anexo A. Listagem dos 88 artigos que deram suporte à pesquisa.

1 A argumentação em discussões sócio-científicas: reflexões a partir de um estudo de caso. SANTOS, W. L. P. dos; MORTIMER, E. F.; SCOTT, P. H. Disponível em: <http://repositorio.unb.br/bitstream/10482/12137/1/ ARTIGO_ArgumentacaoDiscussoesSocioCientificas.pdf >. Acesso em: 03 abr. 2013.

2 A compreensão dos professores sobre as interações CTS evidenciadas pelo questionário VOSTS e entrevista. MIRANDA, E. M.; FREITAS, D. Disponível em: <http://alexandria.ppgect.ufsc.br/files/2012/04/ELISANGELAMATIAS-MIRANDA-DENISE-DE-FREITAS.pdf>. Acesso em: 03 abr. 2013.

3 A construção de um instrumento para análise das representações sociais de docentes engenheiros quanto a CTS. COMIOTTO, T. Disponível em: <http://revistas.utfpr.edu.br/pg/index.php/rbect/article/view/616/465>. Acesso em: 03 abr. 2013.

4 A construção do espaço ibero-americano do conhecimento, os estudos sobre ciência, tecnologia e sociedade e a política científica e tecnológica. DAGNINO, R. Disponível em: <http://www.scielo.org.ar/pdf/cts/v4n12/ v4n12a10.pdf>. Acesso em: 15 fev. 2013.

5 A democracia como balizadora do Ensino das Ciências na Escola: Como discutir este desafio? CASSAB, M. Disponível em: <http://revistas.if.usp.br/rbpec/article/view/50/43>. Acesso em: 04 abr. 2013.

6 A educação científica sob a perspectiva da pedagogia histórico-crítica e do movimento C.T.S. no ensino de ciências. TEIXEIRA, P. M. M. Disponível em: <http://www.scielo.br/pdf/ciedu/v9n2/03.pdf>. Acesso em: 15 fev. 2013.

7 A educação profissional de nível técnico de automobilística do Centro Federal de Educação Tecnológica Celso Suckow da Fonseca (CEFET/RJ): um olhar curricular para as questões ambientais. LEMOS, J. L. S.; LEITE, S. Q. M.; COSTA, M. A. F. da. Disponível em: <http://pepsic.bvsalud.org/scielo.php?pid=S1806-

$58212009000100010 \&$ script=sci_arttext>. Acesso em: 15 fev. 2013

8 A postura do professor em atividades envolvendo a leitura de textos paradidáticos. ASSIS, A.; CARVALHO, F. L. de C. Disponível em: <http://www.cienciamao.usp.br/tudo/exibir.php?midia=rab\&cod= aposturadoprofessoremati>. Acesso em: 15 fev. 2013.

9 A produção de raios $X$ contextualizada por meio do enfoque CTS: um caminho para introduzir tópicos de FMC no ensino médio. SOUZA, A. J. de; ARAÚJO, M. S. T. de. Disponível em: <http://www.scielo.br/pdf/er/n37/ a12n37.pdf>. Acesso em: 15 fev. 2013.

10 A utilização de temas controversos: estudo de caso na formação de licenciandos numa abordagem CTSA. ZUIN, V. G.; FREITAS, D. de. Disponível em: <http://www.ige.unicamp.br/ojs/index.php/cienciaeensino/article/ view/136/129>. Acesso em: 15 fev. 2013

11 Abordagem das relações ciência/tecnologia/sociedade nos conteúdos de funções orgânicas em livros didáticos de química do ensino médio. AMARAL, C. L. C.; XAVIER, E. da S.; MACIEL, M. D. Disponível em: <http://www.if.ufrgs.br/ienci/artigos/Artigo_ID209/v14_n1_a2009.pdf>. Acesso em: 15 fev. 2013.

12 Abordagem de aspectos sociocientíficos em aulas de ciências: possibilidades e limitações. SANTOS, W. L. P. dos; MORTIMER, E. F. Disponível em: <http://www.if.ufrgs.br/ienci/artigos/Artigo_ID214/v14_n2_a2009.pdf>. Acesso em: 15 fev. 2013.

13 Abordagem temática: desafios na educação de jovens e adultos. MUENCHEN, C.; AULER, D. Disponível em: <http://revistas.if.usp.br/rbpec/article/view/61/54>. Acesso em: 04 abr. 2013.

14 Acerca dos possíveis compromissos entre as obras de Gaston Bachelard e de Jean Piaget. EICHLER, L. M. Disponível em: <http://www.cienciasecognicao.org/revista/index.php/cec/article/view/32/36>. Acesso em: 15 fev. 2013.

15 Alfabetização científico-tecnológica para quê? AULER, D.; DELIZOICOV, D. Disponível em: <http:// www.portal.fae.ufmg.br/seer/index.php/ensaio/article/viewFile/44/203>. Acesso em: 15 fev. 2013.

16 Alfabetização científico-tecnológica: um novo "paradigma"? AULER, D. Disponível em: <http:// 150.164.116.248/seer/index.php/ensaio/article/viewFile/60/97>. Acesso em: 15 fev. 2013. 
A área CTS no Brasil vista como rede social: ...

17 Almejando a alfabetização científica no ensino fundamental: a proposição e a procura de indicadores do processo. SASSERON, L. H.; CARVALHO, A. M. P. de. Disponível em: <http://www.if.ufrgs.br/ienci/artigos/ Artigo_ID199/v13_n3_a2008.pdf>.Acesso em: 15 fev. 2013.

18 Análise da perspectiva ciência, tecnologia e sociedade em materiais didáticos. ZUIN, V. G.; FREITAS, D. de; OLIVEIRA, M. R. G. de; PRUDÊNCIO, C. A. V. Disponível em: <http://www.cienciasecognicao.org/pdf/v13/ m318244.pdf>. Acesso em: 15 fev. 2013.

19 Articulação centro de pesquisa - escola básica: contribuições para a alfabetização científica e tecnológica. STRIEDER, R. B.; WATANABE, G.; MUNHOZ, M. G. Disponível em: <http://www.scielo.br/pdf/rbef/v32n3/ v32n3a10.pdf>. Acesso em: 15 fev. 2013.

20 As diferentes correntes epistemológicas e suas implicações para a pesquisa em educação ambiental. SANTOS, M. E. V. M. dos. Disponível em: <http://www.periodicos.rc.biblioteca.unesp.br/index.php/pesquisa/ article/view/6131/4492>. Acesso em: 03 abr. 2013.

21 As trajetórias dos estudos sobre ciência, tecnologia e sociedade e da política científica e tecnológica na IberoAmérica. DAGNINO, R. Disponível em: <http://alexandria.ppgect.ufsc.br/files/2012/03/renato.pdf >. Acesso em: 03 abr. 2013.

22 Automedicação: um tema social para o ensino de química na perspectiva da alfabetização científica e tecnológica. RICHETTI, G. P.; ALVES FILHO, J. P. Disponível em: <http://alexandria.ppgect.ufsc.br/files/2012/03/ Graziela.pdf >. Acesso em: 15 fev. 2013.

23 Biologia, tecnologia e inovação no currículo do ensino médio. AMORIM, A. C. R. de. Disponível em: <http:// www.if.ufrgs.br/ienci/artigos/Artigo_ID38/v3_n1_a1998.pdf>. Acesso em: 15 fev. 2013.

24 Ciência como cultura - paradigmas e implicações epistemológicas na educação. SANTOS, M. E. V. M. dos. Disponível em: <http://quimicanova.sbq.org.br/qn/qnol/2009/vol32n2/42-ED08444.pdf> . Acesso em: 15 fev. 2013.

25 Ciência e tecnologia: implicações sociais e o papel da educação. ANGOTTI, J. A. P. e AUTH, M. A. Disponível em: <http://www.cultura.ufpa.br/ensinofts/artigo4/ctseduca.pdf>. Acesso em: 15 fev. 2013.

26 Ciência, tecnologia e sociedade e formação do engenheiro: análise da legislação vigente. BAZZO, W. A.; MENESTRINA, T. C. Disponível em: <http://revistas.utfpr.edu.br/pg/index.php/rbect/article/viewFile/228/201>. Acesso em: 03 abr. 2013.

27 Ciência, tecnologia e sociedade: a relevância do enfoque CTS para o contexto do ensino médio. PINHEIRO, N. A. M.; SILVEIRA, R. M. C. F.; BAZZO, W. A. Disponível em: <http://www.scielo.br/pdf/ciedu/v13n1/ v13n1a05.pdf>. Acesso em: 15 fev. 2013.

28 Ciência, tecnologia e suas relações sociais: a percepção de geradores de tecnologia e suas implicações na educação tecnológica. SILVEIRA, R. M. C. F.; BAZZO, W. A. Disponível em: <http://www.scielo.br/pdf/ciedu/ v15n3/14.pdf >. Acesso em: 15 fev. 2013.

29 Concepção de currículos de ciências: análise dos princípios ideológicos e pedagógicos dos autores. FERREIRA, S.; MORAIS, A. M.; NEVES, I. P. Disponível em: <http://seer.ufrgs.br/educacaoerealidade/article/ view/7835/8599>. Acesso em: 15 fev. 2013.

30 Concepção de neutralidade e objetividade da ciência e tecnologia na formação de professores de ciências: argumentos para a inserção da história e sociologia da ciência na construção do conhecimento científico. GURGEL, C. M. A.; MARIANO, G. E. Disponível em: <http://revistas.utfpr.edu.br/pg/index.php/rbect/article/view/ 224/197>. Acesso em: 03 abr. 2013.

31 Concepções de professores de química sobre ciência, tecnologia, sociedade e suas inter-relações: um estudo preliminar para o desenvolvimento de abordagens CTS em sala de aula. FIRME, R. N.; AMARAL, E. M. R. do. Disponível em: <http://www.scielo.br/pdf/ciedu/v14n2/a05v14n2.pdf>. Acesso em: 15 fev. 2013.

32 Concepções sobre natureza da ciência e ensino de ciências: um estudo das interações discursivas em um Núcleo de Pesquisa em Ensino de Ciências. BENITE, A. M. C.; VILELA-RIBEIRO, E. B. Disponível em: < http:// revistas.if.usp.br/rbpec/article/download/35/31>. Acesso em: 03 abr. 2013.

33 Configurações curriculares mediante o enfoque CTS: desafios a serem enfrentados na educação de jovens e adultos. MUENCHEN, C.; AULER, D. Disponível em: <http://www.scielo.br/pdf/ciedu/v13n3/a10v13n3.pdf >. Acesso em: 15 fev. 2013. 
Chrispino, Á. et al.

34 Consensos sobre a natureza da ciência: a ciência e a tecnologia na sociedade. VÁZQUEZ ALONSO, A.; MANASSERO MAS, M. A.; ACEVEDO DÍAZ, J. A.; ACEVEDO ROMERO, P. Disponível em: <http://qnesc.sbq. org.br/online/qnesc27/07-ibero-6.pdf>. Acesso em: 15 fev. 2013.

35 Construção de práticas didático-pedagógicas com orientação CTS: impacto de um programa de formação continuada de professores de ciências do ensino básico. TENREIRO-VIEIRA, C.; VIEIRA, R. M. Disponível em: <http://www.scielo.br/pdf/ciedu/v11n2/03.pdf >. Acesso em: 15 fev. 2013.

36 Contextualização e visões de ciência e tecnologia nos livros didáticos de física aprovados pelo PNLEM. MACEDO, C. C. de; SILVA, L. F. Disponível em: <http://alexandria.ppgect.ufsc.br/files/2012/03/cristina.pdf >. Acesso em: 03 abr. 2013.

37 Contextualização no ensino de ciências por meio de temas CTS em uma perspectiva crítica. SANTOS, W. L. P. dos. Disponível em: <http://www.ige.unicamp.br/ojs/index.php/cienciaeensino/article/view/149/120>. Acesso em: 15 fev. 2013.

38 Contribuições pedagógicas e epistemológicas em textos de experimentação no ensino de química. GONÇALVES, F. P.; MARQUES, C. A. Disponível em: <http://www.if.ufrgs.br/ienci/artigos/Artigo_ID151/ v11_n2_a2006.pdf>. Acesso em: 15 fev. 2013.

39 Controvérsia científica, comunicação pública da ciência e museus no bojo do movimento CTS. NAVAS, A. M.; CONTIER, D.; MARANDINO, M. Disponível em: <http://www.cienciamao.usp.br/tudo/ exibir.php?midia=rcen\&cod=_controversiacientificaco>. Acesso em: 15 fev. 2013.

40 Controvérsias sócio-científicas e prática pedagógica de jovens professores. REIS, P.; GALVÃO, C. Disponível em: <http://www.if.ufrgs.br/ienci/artigos/Artigo_ID126/v10_n2_a2005.pdf>. Acesso em: 15 fev. 2013.

41 Criação de um espaço de aprendizagem significativa no planetário do Parque Ibirapuera. ELIAS, D. C. N.; AMARAL, L. H.; ARAÚJO, M. S. T. de. Revista Brasileira de Pesquisa em Educação em Ciências, Belo Horizonte, v. 4, n. 3, p. 1-15, jan./abr. 2007.

42 Discussões acerca do aquecimento global: uma proposta CTS para abordar esse tema controverso em sala de aula. VIEIRA, K. R. C. F.; BAZZO, W. A. Disponível em: <http://www.ige.unicamp.br/ojs/index.php/ cienciaeensino/article/view/155/119>. Acesso em: 15 fev. 2013.

43 Do estado da arte da pesquisa em educação em ciências: linhas de pesquisa e o caso "ciência-tecnologiasociedade". CACHAPUZ, A.; PAIXÃO, F.; LOPES, J. B.; GUERRA, C. Disponível em: <https://www.furb.br/2005/ arquivos/328482-882001/CACHAPUZ.pdf>. Acesso em: 15 fev. 2013.

44 Educação ambiental desde o enfoque ciência/tecnologia/sociedade (CTS) - um possível caminho. COPELLO, M. I.; LIMA, C. A. de. Disponível em: <http://www.periodicos.rc.biblioteca.unesp.br/index.php/pesquisa/article/ view/6149/4508>. Acesso em: 03 abr. 2013.

45 Educação ambiental e a tríade ciência/tecnologia/sociedade (CTS): uma proposta didática desenvolvida no ensino médio, São José do Planalto, Pedra Preta. FREITAS, M. N. de; RAMOS, N. A.; ARAÚJO, P. K. B.; PASA, M. C. Disponível em: <http://200.129.241.94/index.php/biodiversidade/article/view/99/56>. Acesso em: 15 fev. 2013.

46 Educação científica e movimento CTS no quadro das tendências pedagógicas no Brasil. TEIXEIRA, P. M. M. Disponível em: <http://ufpa.br/ensinofts/artigos2/v3n1a7.pdf >. Acesso em: 03 abr. 2013.

47 Educação científica humanística em uma perspectiva freireana: resgatando a função do ensino de CTS. SANTOS, W. L. P. dos. Disponível em: <http://alexandria.ppgect.ufsc.br/files/2012/03/WILDSON. pdf > . Acesso em: 03 abr. 2013.

48 Educação CTS: uma proposta para a formação de cientista e engenheiros. DIAS, R. B.; SERAFIM, M. P. Disponível em: <http://www.scielo.br/pdf/aval/v14n3/a05v14n3.pdf>. Acesso em: 15 fev. 2013.

49 Educação CTSA: obstáculos e possibilidades para sua implementação no contexto escolar. RICARDO, E. C. Disponível em: <http://www.ige.unicamp.br/ojs/index.php/cienciaeensino/article/viewFile/160/113>. Acesso em: 15 fev. 2013.

50 Educação em física: discutindo ciência, tecnologia e sociedade. ANGOTTI, J. A. P.; MION, R. A.; BASTOS, F. P. de. Disponível em: <http://www.scielo.br/pdf/ciedu/v7n2/04.pdf >. Acesso em: 15 fev. 2013. 
A área CTS no Brasil vista como rede social: ...

51 Enfoque ciência-tecnologia-sociedade: pressupostos para o contexto brasileiro. AULER, D. Disponível em: <http://www.ige.unicamp.br/ojs/index.php/cienciaeensino/article/viewFile/147/109>. Acesso em: 15 fev. 2013.

52 Enfoque CTS na pesquisa em Educação em Ciências: extensão e disseminação. PANSERA-DE-ARAÚJO, M. C.; GEHLEN, S. T.; MEZALIRA, S. M.; SCHEID, N. M. J. Disponível em: <http://revistas.if.usp.br/rbpec/article/ download/22/21>. Acesso em: 03 abr. 2013.

53 Exposições museológicas para aprendizagem de física em espaços formais de educação: um estudo de caso. PORTO, F. S.; ZIMMERMANN, E.; HARTMANN, A. M. Disponível em: <http://www.periodicos.ufsc.br/index.php/ fisica/article/view/13510/12385>. Acesso em: 15 fev. 2013.

54 Formação contínua de professores para uma orientação CTS do ensino de química: um estudo de caso. REBELO, I. S.; MARTINS, I. P.; PEDROSA, M. A. Disponível em: <http://qnesc.sbq.org.br/online/qnesc27/06ibero-5.pdf>. Acesso em: 15 fev. 2013.

55 Formação inicial de professores de ciências: perspectiva discursiva na educação CTS. CASSIANI, S.; VON LINSINGEN, I. Disponível em: <http://www.scielo.br/pdf/er/n34/08.pdf>. Acesso em: 15 fev. 2013.

56 História das ciências no ensino de ciências: contribuições dos recursos audiovisuais. REZENDE, L. A. Disponível em: <http://www.cienciaemtela.nutes.ufrj.br/artigos/0208rezende.pdf>. Acesso em: 15 fev. 2013.

57 Investigando a metodologia dos problemas geradores de discussões: aplicações na disciplina de física no ensino de engenharia. MACHADO, V.; PINHEIRO, N. A. M. Disponível em: <http://www.scielo.br/pdf/ciedu/ v16n3/v16n3a02.pdf>. Acesso em: 15 fev. 2013.

58 Concepções de professores de química sobre ciência, tecnologia, sociedade e suas inter-relações: um estudo preliminar para o desenvolvimento de abordagens CTS em sala de aula. FIRME, R. N.; AMARAL, E. M. R. do. Disponível em: <http://www.scielo.br/pdf/ciedu/v14n2/a05v14n2.pdf >. Acesso em: 15 fev. 2013.

59 Mangás e sua utilização pedagógica no ensino de ciências sob a perspectiva CTS. VON LINSINGEN, L. Disponível em: <http://www.ige.unicamp.br/ojs/index.php/cienciaeensino/article/view/125/110>. Acesso em: 15 fev. 2013.

60 Materiais instrucionais numa perspectiva CTSA: uma análise de unidades didáticas produzidas por professores de química em formação continuada. MARCONDES, M. E. R.; CARMO, M. P. do; SUART, R. C.; SILVA, E. L. da; SOUZA, F. L.; SANTOS JR., J. B.; AKAHOSHI, L. H. Disponível em: <http://www.if.ufrgs.br/ ienci/artigos/Artigo_ID218/v14_n2_a2009.pdf>. Acesso em: 15 fev. 2013.

61 Nanociência e nanotecnologia como temáticas para discussão de ciência, tecnologia, sociedade e ambiente SIQUEIRA-BATISTA, R.; MARIA-DA-SILVA,L.; SOUZA, R. R. M.; PIRES-DO-PRADO, H. J.; SILVA, C. A. da; RÔÇAS, G.; HELAYËL-NETOS, J. A.; OLIVEIRA, A. L. de. Disponível em: <http://www.scielo.br/pdf/ciedu/v16n2/ v16n2a14.pdf > . Acesso em: 15 fev. 2013.

62 Narrativa, mito, ciência e tecnologia: o ensino de ciências na escola e no museu. LEAL, M. C.; GOUVÊA, G. Disponível em: <http://www.portal.fae.ufmg.br/seer/index.php/ensaio/article/view/18/49>. Acesso em: 15 fev. 2013.

63 O currículo de física: inovações e tendências nos anos noventa. VANNUCCHI, A.; CARVALHO, A. M. P. de. Disponível em: <http://www.if.ufrgs.br/ienci/artigos/Artigo_ID/v1_n1_a1.doc >. Acesso em: 15 mar. 2013.

64 O emprego de parâmetros físicos e químicos para avaliação da qualidade de águas naturais: uma proposta para a educação química e ambiental na perspectiva CTSA. ZUIN, V. G.; IORIATTI, M. C. S. e MATHEUS, C. E. Disponível em: <http://qnesc.sbq.org.br/online/qnesc31_1/02-QS-5507.pdf>. Acesso em: 15 mar. 2013.

650 ensino de química no curso técnico integrado PROEJA em metalurgia e materiais (IFES campus Vitória): análise das percepções discentes. KRUGER, J. G.; LEITE, S. Q. M. Disponível em: <http:// www.cienciasecognicao.org/revista/index.php/cec/article/view/297/170>. Acesso em: 15 mar. 2013.

66 O papel do engenheiro na sociedade. DAGNINO, R.; NOVAES, H. T. Disponível em: <http:// revistas.utfpr.edu.br/ct/tecnologiaesociedade/index.php/000/article/view/7/7>. Acesso em: 15 mar. 2013.

67 O pró-álcool e algumas relações CTS concebidas por alunos de $6^{\mathrm{a}}$ série do ensino fundamental. ANDRADE, E. C. P.; CARVALHO, L. M. Disponível em: <http://www.scielo.br/scielo.php?pid=S1516-

$73132002000200003 \&$ script=sci_arttext >. Acesso em: 15 mar. 2013. 
Chrispino, Á. et al.

68 O que foge do olhar das reformas curriculares: nas aulas de Biologia, o professor como escritor das relações entre ciência, tecnologia e sociedade. AMORIM, A. C. R. de. Disponível em: <http://www.cultura.ufpa.br/ensinofts/ artigo4/ctsbiologia.pdf>. Acesso em: 15 mar. 2013.

69 Os grupos de pesquisa em ciência, tecnologia e sociedade no Brasil. ARAUJO, R. F. Disponível em: <http:// www.revistabrasileiradects.ufscar.br/index.php/cts/article/view/50/4>. Acesso em: 15 mar. 2013.

70 Perspectiva educacional CTS: aspectos de um campo em consolidação na América Latina. VON LINSINGEN, I. Disponível em: <http://www.ige.unicamp.br/ojs/index.php/cienciaeensino/article/view/150/108>. Acesso em: 15 mar. 2013.

71 Pesquisa em ensino de ciências como ciências humanas aplicadas. DELIZOICOV, D. Disponível em: <http:// www.periodicos.ufsc.br/index.php/fisica/article/view/6430/5946>. Acesso em: 15 mar. 2013.

72 Possibilidades de um caso simulado CTS na discussão da poluição ambiental. FLOR, C. C. Disponível em: <http://www.periodicos.ufsc.br/index.php/fisica/article/view/6430/5946>. Acesso em: 15 mar. 2013.

73 Produção e consumo da energia elétrica: a construção de uma proposta baseada no enfoque ciência-tecnologia-sociedade-ambiente (CTSA). BERNARDO, J. R. R.; VIANNA, D. M.; FONTOURA, H. A. da. Disponível em: <http://www.ige.unicamp.br/ojs/index.php/cienciaeensino/article/view/157/114>. Acesso em: 15 mar. 2013.

74 Professores de física em formação inicial: o ensino de física, a abordagem CTS e os temas controversos. SILVA, L. F.; CARVALHO, L. M. de. Disponível em: <http://www.if.ufrgs.br/ienci/artigos/Artigo_ID211/ v14_n1_a2009.pdf>. Acesso em: 15 mar. 2013.

75 Projetos curriculares interdisciplinares e a temática da energia. BUCUSSI, A. A.; OSTERMANN, F. Disponível em: <http://www.if.ufrgs.br/eenci/artigos/Artigo_ID14/pdf/2006_1_1_14.pdf>. Acesso em: 15 mar. 2013.

76 Reflexões para a implementação do movimento CTS no contexto educacional brasileiro. AULER, D.; BAZZO, W. A. Disponível em: <http://www.cultura.ufpa.br/ensinofts/artigo4/ctsbrasil.pdf>. Acesso em: 15 mar. 2013.

77 Ressignificação curricular: contribuições da investigação temática e da análise textual discursiva. TORRES, J. R.; GEHLEN, S. T.; MUENCHEN, C.; GONÇALVES, F. P.; LINDEMANN, R. H.; GONÇALVES, F. J. F. Disponível em: <http://www.fae.ufmg.br/abrapec/revistas/V8N2/v8n2a4.pdf>. Acesso em: 15 mar. 2013.

78 Saúde, como compreensão de vida: avaliação para inovação na educação em saúde para o ensino fundamental. DINIZ, M. C. P.; SCHALL, V. T.; OLIVEIRA, T. C. de. Disponível em: <http://www.portal.fae.ufmg.br/ seer/index.php/ensaio/article/view/264/332>. Acesso em: 15 mar. 2013.

79 Temas sociocientíficos (cachaça e cerveja) em aulas práticas de química na educação profissional: uma abordagem CTS. SANTOS, M. S. dos; AMARAL, C. L. C.; MACIEL, M. D. Disponível em: <http://www.pg. utfpr.edu.br/depog/periodicos/index.php/rbect/article/viewFile/620/552>. Acesso em: 15 mar. 2013.

80 Tomada de decisão para ação social responsável no ensino de ciências. MORTIMER, E. F.; SANTOS, W. L. P. dos. Disponível em: <http://www2.fc.unesp.br/cienciaeeducacao/viewarticle.php?id=115\&layout=abstract>. Acesso em: 15 mar. 2013.

81 Um currículo de ciências voltado para a compreensão por todos. MILLAR, R. Disponível em: <http://ufpa.br/ ensinofts/artigo4/cienciaparatodos.pdf>. Acesso em: 15 mar. 2013.

82 Um exercício de uso racional da energia: o caso do transporte coletivo. DIAS, R. A.; BALESTIERI, J. A. P.; MATTOS, C. R. de. Disponível em: <http://www.periodicos.ufsc.br/index.php/fisica/article/view/6288/12774>. Acesso em: 15 mar. 2013.

83 Um olhar sobre a produção científica na área de nutrição a partir da perspectiva CTS: apontamentos para a formação superior em saúde. ELIAS, R. C.; FONSECA, A. B. C. da. Disponível em: <http://alexandria. ppgect.ufsc.br//numero_1_2009/Rosane.pdf>. Acesso em: 15 mar. 2013.

84 Uma abordagem CTS ao ensino de ciências: oficina interativa sobre a regulamentação do uso científico de animais no Brasil. FILIPECKI, A. T.; AMARAL, A. M. R. Disponível em: <http://www.cienciaemtela.nutes.ufrj.br/ artigos/0110_filipecki.pdf>. Acesso em: 15 mar. 2013.

85 Uma análise de pressupostos teóricos da abordagem C-T-S (ciência-tecnologia-sociedade) no contexto da educação brasileira. MORTIMER, E. F.; SANTOS, W. L. P. dos. Disponível em: <http://ufpa.br/ensinofts/artigos2/ wildsoneduardo.pdf>. Acesso em: 15 mar. 2013. 
A área CTS no Brasil vista como rede social: ...

86 Uma experiência com o projeto Manhattan no ensino fundamental. SAMAGAIA, R.; PEDUZZI, L. O. Q.

Disponível em: <http://www2.fc.unesp.br/cienciaeeducacao/viewarticle.php?id=24\&layout=abstract>. Acesso em:

15 mar. 2013.

87 Uma visão comparada do ensino em ciência, tecnologia e sociedade na escola e em um museu de ciência. GOUVÊA, G.; LEAL, M. C. Disponível em: <http://www2.fc.unesp.br/cienciaeeducacao/viewarticle.php?id=113>. Acesso em: 15 mar. 2013.

88 Visões de contextualização de professores de química na elaboração de seus próprios materiais didáticos. MARCONDES, M. E. R.; SILVA, E. L. da. Disponível em: <http://www.portal.fae.ufmg.br/seer/index.php/ensaio/ article/viewArticle/262>. Acesso em: 15 mar. 2013.

Artigo recebido em 23/06/12. Aceito em 12/10/12. 